\title{
Database of Masaryk University's Vegetation Research in Siberia
}

\author{
Milan Chytrý
}

\begin{abstract}
The Database of Masaryk University's Vegetation Research in Siberia (GIVD ID 00-RU-002) contains records from 100-m² vegetation plots collected since 2003 during reasearch expeditions of Masaryk University in Siberia and Bashkortostan, namely in the Southern Urals, Altai and Western Sayan Mountains, and Central Yakutia. Most plots were recorded in forest, steppe and alpine tundra vegetation. Each plot contains a full record of vascular plants, terricolous bryophytes and macrolichens, supplemented with measurements of soil properties and hemispheric canopy photographs. Subsets of plots contain records of modern pollen deposition, molluscan community composition and herbaceous biomass. The database is used for biodiversity studies with reference to palaeoecology and modern vegetation-environment relationships.
\end{abstract}

Keywords: forest; Russia; steppe; taiga; tundra.

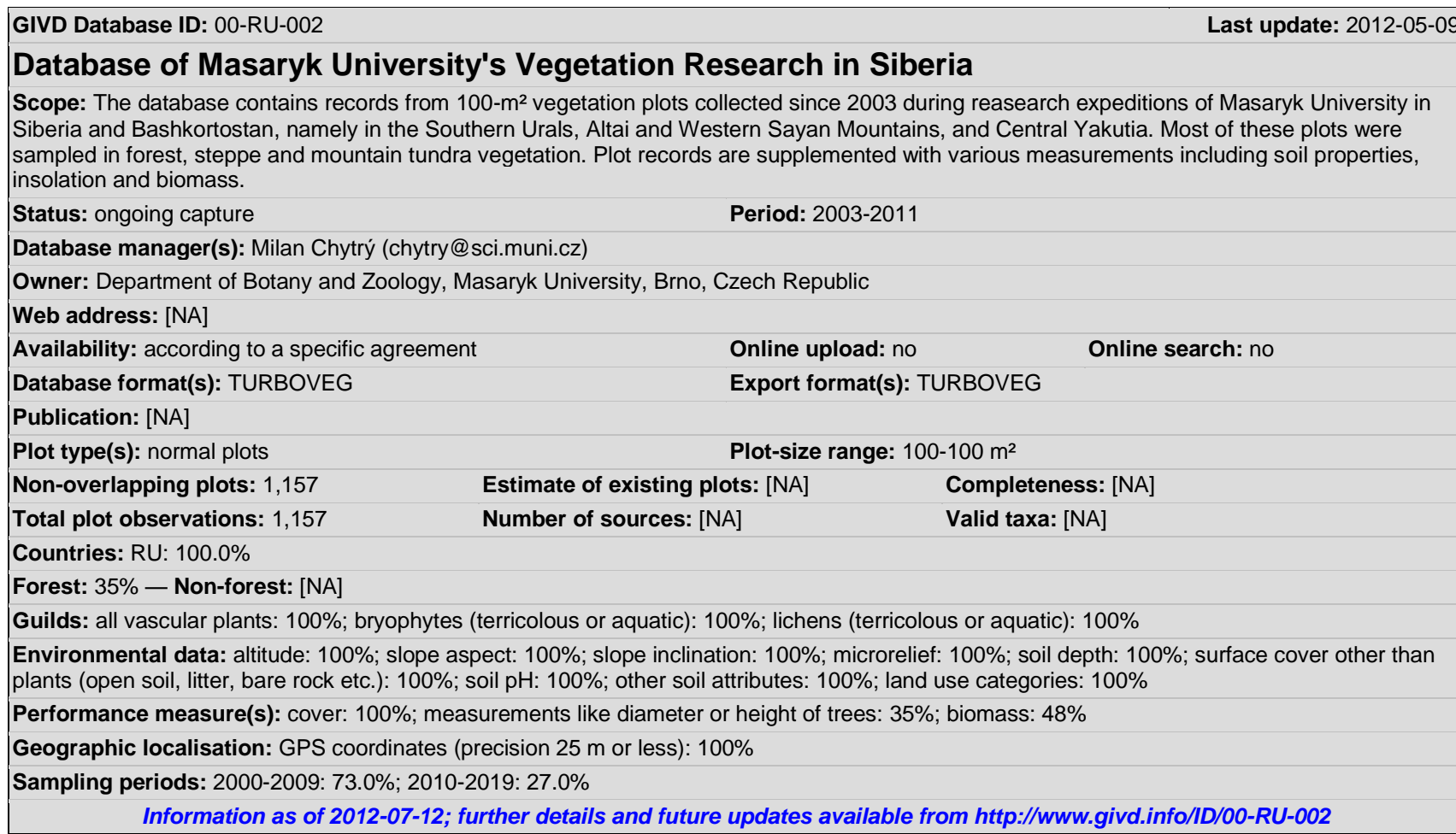

Milan Chytrý (chytry@ sci.muni.cz)

Department of Botany and Zoology, Masaryk University, Kotlárská 2, CZ-61137 Brno, CZECH REPUBLIC 